\title{
Repenser l'ordre européen (1795-1802) - De la société des rois aux droits des nations
}

Jean-Yves Guiomar

\section{Q OpenEdition \\ 1 Journals}

Édition électronique

URL : https://journals.openedition.org/ahrf/8053

DOI : 10.4000/ahrf.8053

ISSN : 1952-403X

Éditeur :

Armand Colin, Société des études robespierristes

Édition imprimée

Date de publication : 1 décembre 2006

Pagination : 196-199

ISSN : 0003-4436

Référence électronique

Jean-Yves Guiomar, «Repenser l'ordre européen (1795-1802) - De la société des rois aux droits des nations ", Annales historiques de la Révolution française [En ligne], 346 | Octobre/Décembre 2006, mis en ligne le 10 juillet 2008, consulté le 24 avril 2022. URL : http://journals.openedition.org/ahrf/8053 ;

DOI : https://doi.org/10.4000/ahrf.8053

Ce document a été généré automatiquement le 24 avril 2022.

Tous droits réservés 


\title{
Repenser l'ordre européen (1795-1802) - De la société des rois aux droits des nations
}

\author{
Jean-Yves Guiomar
}

\section{RÉFÉRENCE}

Marc Belissa, Repenser l'ordre européen (1795-1802) - De la société des rois aux droits des nations, Paris, Kimé, 2006, 472 p., ISBN 2-84174-383-7, $40 €$.

1 Marc Belissa poursuit ici son "histoire politique des relations entre les peuples » commencée dans Fraternité universelle et intérêt national (1998). Son fil conducteur est qu'entre 1795 et 1802 « les nations font leur entrée dans la sphère internationale ». « La souveraineté nationale, écrit-il, devient un principe légitimant, concurrent de la souveraineté dynastique ou personnelle».

2 L'auteur recourt aux sources françaises, mais fait aussi une large place aux sources anglaises, ainsi qu'aux contre-révolutionnaires (Burke, Mallet du Pan, d'Ivernois et surtout Gentz). Ce n'est pas la moindre richesse de ce travail.

31795 : la France a signé d'importants traités de paix, elle a avalé la Belgique et pris pied sur la rive gauche du Rhin, atteignant ses « frontières naturelles ». Puis elle s'entoure d'une série de Républiques-sœurs. La paix générale en 1801 et 1802 parachève le triomphe. Triomphe si énorme que le Directoire n'y a pas résisté. «Dans le discours thermidorien, expose Belissa, l'idée que la paix ne peut être que glorieuse et que le peuple français doit reprendre sa place parmi les nations revient donc en permanence ». Alors qu'elle est fondée sur le rejet brutal des dynasties, la République victorieuse doit établir avec elles des relations pacifiques. La cession de Venise à l'Autriche semble aller dans ce sens. Mais la mainmise sur le reste de l'Italie du Nord, la création de la République romaine et la prise de contrôle de la Suisse contredisent cette volonté affichée de coexistence. S'ensuivent la deuxième coalition (1798) et l'assassinat 
des plénipotentiaires français à Rastadt (28 avril 1799), qui scelle l'échec de la tentative directoriale, intenable gageure. Place à Bonaparte qui rejette le bellicisme directorial, rompt avec la politique extérieure des républicains avancés et veut mettre l'honorabilité de la France au-dessus de sa gloire. Un temps, «la France retrouve sa place dans la "balance européenne" ", mais "en perdant sa vocation républicaine cosmopolitique ".

4 C'est sur cette stase que se clôt l'ouvrage, qui vise à démontrer que 1802 est une date essentielle, un moment d'équilibre certes fragile, mais où «un ordre intégrant la France aurait pu se construire ». Ce conditionnel souligné par l'auteur sous-entend, me semble-t-il, une restriction, d'autant que Marc Belissa écrit en conclusion : "On peut donc dire que si l'Europe "contemporaine" naît d'une certaine manière au congrès de Vienne, c'est autour de 1802 que l'Europe "moderne" disparaît ». L'analyse proposée est donc celle d'une disparition, c'est-à-dire d'un travail du négatif, davantage que l'avènement d'une positivité.

5 L'auteur montre qu'au sein de ce négatif, du positif tente d'émerger, émerge presque dans un tournant dont l'essentiel est que l'ancien droit des gens, " conçu comme un droit commun à tous les peuples tend à s'effacer devant un droit positif entre les nations ». C'est ce que développe une première partie chronologique, suivie d'une deuxième plus synthétique. La première partie se lit agréablement, la seconde est plus ardue, comme le chapitre sur "L'architecture géopolitique continentale», long et compliqué. Il est vrai qu'il n'est pas facile de tenir tous les fils d'une politique extérieure directoriale dont on peut se demander si elle n'est pas un échec parce qu'elle est surtout un gigantesque non-sens, tant elle voudrait - dit-elle - bâtir un ordre européen stable entre des puissances où il n'y a que calculs. Sans oublier ceux des directoriaux euxmêmes, qui jettent en permanence un sérieux doute sur leur intégrité intellectuelle. Si pour la plupart la sincérité républicaine n'est pas en cause, ils ne cessent de la malmener, perdant en Italie du Nord - dès avril 1797 ! - la maîtrise du pouvoir. La politique intérieure aussi leur glisse entre les mains. Peu de moments de l'histoire offrent un tel défi aux historiens : comment mettre de la clarté là où les acteurs sont menés par des pensées si confuses et si contradictoires?

Marc Belissa a raison de voir dans le moment directorial une période cruciale, mais je crois qu'on peut s'interroger quand il le présente comme du positif, à savoir l'entrée des nations dans l'ordre international en 1795. Il me semble que si l'on y voyait d'emblée un échec, l'analyse en serait facilitée. J'appuierai mon hypothèse sur quatre remarques.

- Belissa écarte les « raisons économiques et sociales qui sont hors de mon propos». Certes, s'il les avait intégrées, son livre aurait peut-être doublé de volume. Mais c'est pourtant luimême qui évoque sans cesse l'économie. Ainsi, il recourt fréquemment aux rapports faits par Joseph Eschassériaux. Or celui-ci a constamment en vue la nécessité pour la France de relancer son économie, support de sa puissance politique internationale. Belissa rappelle aussi l'importance des considérations économiques dans les traités depuis Utrecht (1713), et écrit que la gloire « de la République directoriale se place presque uniquement sur le terrain économique : la puissance commerciale est la mesure de l'hégémonie dans un ordre international hétérogène » (p. 364). Et : « Les clauses commerciales des projets de traités du Directoire sont bien l'expression d'une volonté de domination nationale sur les marchés européens et coloniaux » (ibid.). Voilà qui est parfaitement dit, mais rend peu 
compréhensible l'exclusion de l'économie, premier terrain sur lequel les directoriaux ont été quasiment nuls.

- Les passages cités de la p. 364 se terminent par : « Reste à savoir si cette domination [économique et commerciale] doit être exclusive ou si elle doit être ouverte à toutes les nations ». Question centrale, que je mets en rapport avec l'importance que Belissa donne à l'ouvrage de Barère, La Liberté des mers ou Le gouvernement anglais dévoilé (an VI, édité aux frais de l'auteur), où il voit une « théorisation beaucoup plus poussée que chez les autres publicistes [du moment] de l'opposition entre puissance continentale et puissance maritime ».

L'idée maîtresse de Barère est que les continents doivent régir les océans et donc les îles, et non l'inverse. C'est évidemment la Grande-Bretagne qui est visée, puissance maritime exclusive, despotique, qu'il s'agit de vaincre par les armes pour bâtir une puissance maritime commune démocratique. L'idée est séduisante, elle a pour elle la clarté de l'évidence : en effet, du XVIII ${ }^{\mathrm{e}}$ au XX ${ }^{\mathrm{e}}$ siècle, une partie considérable du droit international a porté sur la liberté de circulation sur les mers et sur le commerce que cette liberté rend possible. Mais - autre échec du régime - ce droit s'est élaboré dans la paix beaucoup plus que par la guerre.

Ce n'est pas ici le lieu de discuter cette question sur le fond. Mais je ferai plusieurs observations. D'abord, si l'ouvrage de Barère est si important, comment comprendre qu'il n'ait guère précédemment retenu l'attention des historiens (ni Raymond Guyot dans son livre sur le Directoire, ni Albert Sorel au tome V de son Europe et la Révolution française, ni Georges Lefebvre dans son cours sur le Directoire ne l'évoquent). Le livre n'a d'ailleurs jamais été réédité - si l'on écarte la méchante publication en 1942 d'extraits par le collaborateur Jean Marchand, séduit par les imprécations de Barère contre Carthage. Avonsnous ici affaire à un travail théorique, ou à un jet de haine brûlante, déclinée sur tous les modes? Le ressassement ne s'arrête d'ailleurs pas là : en l'an XII, Barère entame la publication d'un journal, le Mémorial anti-britannique (donc du pur négatif), qui se poursuit en l'an XIII dans un Mémorial européen (du positif, cette fois?). Toujours en l'an XIII, Barère publie Les Anglais et le XIX ${ }^{e}$ siècle, pure répétition des condamnations antérieures, qui ne pouvait fournir aucun élément utilisable par les politiques et les juristes. Aussi l'essor du droit international depuis la fin du XVIII ${ }^{\mathrm{e}}$ siècle ne doit-il rien à Barère.

Si l'on devait aller chercher dans la période 1795-1802 la conscience de la nécessité de dépasser les affrontements mercantilistes, source essentielle des guerres du XVIII ${ }^{\mathrm{e}}$ siècle, on pourrait par exemple la trouver dans la réédition en l'an IV de l'ouvrage majeur de Véron de Forbonnais, Les Éléments du commerce, dont la précédente édition datait de 1766. Loin des pitoyables appels de Barère à l'invasion de l'Angleterre, cet ouvrage porteur d'une information sérieuse sur l'essor économique de ce pays témoigne des échanges intellectuels entre les deux côtés du Channel tout au long du XVIII ${ }^{\mathrm{e}}$ siècle, échanges qui reprendront dès 1815 et aboutiront - entre autres - en 1860 au traité de libre échange entre les deux pays, prévu dès 1713 et brièvement apparu en 1786 .

Autre élément intéressant de la période à ce sujet : Friedrich Gentz a publié en 1800 un Essai sur l'état actuel de l'administration des finances et de la richesse nationale de la Grande-Bretagne, qui prend judicieusement en compte l'économie et fait litière des illusions des Français du temps sur le caractère prétendument factice de la puissance britannique.

- Tout cela me conduit à ma troisième observation. Car Barère (et les directoriaux de même) a beau invoquer dans son livre la production et le commerce, il n'est pas conscient d'une évidence : l'essor économique anglais depuis la seconde moitié du XVIII ${ }^{\mathrm{e}}$ siècle (Manchester a 10000 habitants en 1727, 95000 en 1801), qui fait que si l'Angleterre veut la maîtrise des 
océans, c'est pour servir sa puissance financière et commerciale et non pour le simple plaisir de jouer les tyrans. Et cet essor s'appelle la croissance, notion inconnue des révolutionnaires français. Si l'Angleterre est alors la seule à l'avoir amorcée, le continent ne tarde pas à suivre, et dès qu'en France, en Belgique, en Allemagne, en Suisse, la production et le besoin de débouchés s'accroissent, alors le domaine de l'International Law inventée par Bentham en 1789 commence à s'élaborer et à s'étendre : preuve a posteriori du lien fondamental entre économie, commerce et droit international. C'est sur ce terrain - non exclusivement mais principalement - que le droit maritime, le droit international public et privé (ce dernier n'étant pas le moins important) connaissent leur développement, aux antipodes $\mathrm{du}$ bellicisme de Barère, qui est en l'an VI, à mon avis, un homme dépassé.

- Les remarques précédentes ne contredisent en rien le fait que l'ouvrage de Marc Belissa nous livre un riche et passionnant dossier sur l'amorce d'un droit inter-national (le tiret est de lui) entre 1795 et 1802. Je me vois cependant obligé de poser une dernière question. Lorsqu'il écrit qu'après 1815 « le droit des gens, conçu comme un droit commun à tous les peuples, tend à s'effacer devant un droit positif entre les nations ", ce droit positif doit-il être référé aux nations, ou n'est-ce pas plutôt aux États ? Or si la phase analysée par Belissa montre une chose, c'est bien que l'échec du Directoire a tenu d'abord à son incapacité à mettre sur pied un État capable d'instaurer les conditions politiques et juridiques propres à la reprise de la vie économique tout en intégrant la formidable mutation initiée avec succès en 1789. Le dernier à s'en apercevoir ne fut pas Bonaparte, qui s'attacha à remettre la France au travail, même s'il se contredit vite en se laissant emporter par le démon de Bellone.

Le travail que Marc Belissa a entrepris à travers ouvrages et articles est d'une grande importance et nous apporte d'utiles clarifications, comme sur la difficile notion de «droit des gens », qui court dans les études, les documents et les traités depuis au moins le XVII ${ }^{\mathrm{e}}$ siècle jusqu'au $\mathrm{XX}^{\mathrm{e}}$, et est encore parfois utilisée mais d'une façon qui ne permet plus d'en saisir le sens. Son dernier ouvrage aborde de front un moment complexe et subtil, dont les enjeux totalement nouveaux sont certes saisis par les protagonistes de la période, mais de toute évidence pas complètement d'où, par exemple, le penchant d'un Barère pour des approches qui me paraissent régressives. Ce moment est celui où tous en Europe, républicains comme tenants de l'ordre dynastique, prennent conscience que les peuples ne veulent plus être de simples spectateurs, ou des pions, dans une partie se jouant au-dessus d'eux qui disposerait de leur sort sans se soucier de ce qu'ils en pensent. Cette conscience s'incarne dans la notion de souveraineté nationale, source d'un formidable progrès par rapport à l'Ancien Régime, mais source aussi de difficultés nouvelles - Saint-Simon s'en est aperçu dès le début du $\mathrm{XIX}^{\mathrm{e}}$ siècle - dues à la question, encore mal tranchée au XXI ${ }^{\mathrm{e}}$ siècle, de savoir comment arbitrer entre des sujets collectifs souverains jaloux de leurs intérêts et de leur indépendance, autrement que par des accords bi- ou multilatéraux qui ne répondent que trop faiblement à la recherche de cette paix perpétuelle qu'un Kant avait tant désirée. 